\title{
Effect of Aging on Compressive Strength, Fluoride Release, Water Sorption, and Solubility of Ceramic-reinforced Glass Ionomers: An In Vitro Study
}

\author{
Shaimaa H Dawood ${ }^{1}$, Mohamed M Kandil ${ }^{2}$, Dalia I El-Korashy ${ }^{3}$
}

\begin{abstract}
Aim: The aim of this study was to evaluate the effect of aging on compressive strength; fluoride release; water sorption; and solubility of ceramicreinforced (amalgomer CR), resin-modified (Fuji VIII), and high-viscosity (Equia fill) glass ionomers.

Materials and methods: A total of 141 specimens were prepared, 47 for each restorative material. For compressive strength testing, cylindrical specimens ( $4 \mathrm{~mm}$ diameter and $6 \mathrm{~mm}$ thickness) were prepared and tested after 24 hours and 6 months of storage in deionized water ( $n=10$ ). Disk-shaped specimens with $6 \mathrm{~mm}$ diameter and $3 \mathrm{~mm}$ thickness were prepared for fluoride release $(n=7)$ and measured at 24,48 hours, 7 days, 1,3 , and 6 months. Disk-shaped specimens ( $15 \mathrm{~mm}$ diameter and $1 \mathrm{~mm}$ thickness) were prepared for water sorption and solubility testing and measured at 7 days, 1, 3, and 6 months ( $n=5$ ). Two-way analysis of variance (ANOVA) and one-way ANOVA were used for statistical analysis of data. Results: Amalgomer CR and Fuji VIII showed the highest compressive strength, whereas Equia fill showed the lowest value after 24 hours. After 6 months of aging, the compressive strength of amalgomer CR was significantly decreased. Amalgomer CR showed the highest initial fluoride release followed by Fuji VIII and Equia fill. Equia fill showed the least amount of water sorption and solubility followed by Fuji VIII and amalgomer CR. Significance: Zirconia fillers enhanced the properties of glass ionomer; however, this improvement was dramatically reduced with water aging. Keywords: Amalgomer CR, Ceramic-reinforced glass ionomer, Compressive strength, Equia fill, Fluoride release, Fuji VIII, High-viscosity glass ionomer, Resin-modified glass ionomer, Solubility, Water sorption.
\end{abstract}

Journal of Contemporary Dentistry (2019): 10.5005/jp-journals-10031-1260

\section{INTRODUCTION}

Caries at the tooth/restoration interface is considered one of the most common reasons for replacement of restorations. When dental materials release fluoride, it is expected that, besides restoring function, they may control the recurrence of caries and contribute to reduction of caries incidence in the whole dentition. ${ }^{1}$

Glass ionomer was introduced by Wilson and Kent in 1972. It is characterized by increasing teeth resistance to recurrent caries because of fluoride release and its ability to recharge fluoride again along with its ability for chemical bonding to dental substrates and close thermal expansion coefficient to that of tooth structure. The poor mechanical characteristics of conventional glass ionomer limit its extensive use as a restorative material in stress-bearing areas. ${ }^{2}$

Therefore, different trials to modify glass ionomer materials have been introduced to overcome these drawbacks. Resinmodified glass ionomer or hybrid ionomer was released on the market in 1992. ${ }^{3}$ These are conventional glass ionomers with the addition of a small quantity of resins (4.5-6\%) such as hydroxyethyl methacrylate (HEMA) or Bis GMA as well as initiators involved in the polymerization reaction. In general, resin-modified glass ionomers were reported to show better mechanical properties than conventional types. ${ }^{4}$ Fuji VIII (GC America) is an auto-cured resin-modified glass ionomer; both the acid-base reaction and resin polymerization are initiated once the components are mixed. ${ }^{5}$

The development of the high viscosity or packable glass ionomer in the mid-1990s resulted in materials with improved mechanical properties. ${ }^{6}$ The powder is chemically modified during manufacturing to decrease the calcium content and thus limit the production of calcium polyalkenoate chains that are highly water soluble. This allows faster maturation of the material, and the
${ }^{1-3}$ Department of Biomaterials, Faculty of Dentistry, Ain Shams University, Cairo, Egypt

Corresponding Author: Shaimaa H Dawood, Department of Biomaterials, Faculty of Dentistry, Ain Shams University, Cairo, Egypt, Phone: +20 1061296044, e-mail: Shaimaahamdy@dent.asu.edu.eg

How to cite this article: Dawood SH, Kandil MM, El-Korashy DI. Effect of Aging on Compressive Strength, Fluoride Release, Water Sorption, and Solubility of Ceramic-reinforced Glass Ionomers: An In Vitro Study. J Contemp Dent 2019;9(2):78-84.

Source of support: Nil

Conflict of interest: None

calcium in conventional glass ionomer cement has been largely replaced with strontium. The relatively higher viscosity is the result of the addition of polyacrylic acid to the powder, increase in its concentration and molecular weight, and reduction of the grain size of the glass particles. ${ }^{7}$

In 2007, a trial called Equia was introduced to combine the main advantages of the high-viscosity glass ionomer with a nano-filled, light curing coat to provide more protection in the early setting stage. Equia coat (GC America) is a low-viscosity nano-filled surfacecoating resin, recommended by the manufacturer to be applied over Equia fill restoration occluding any surface cracks and porosity and hence increasing the physical properties, the wear resistance, and toughness of the restoration. ${ }^{8}$

A more recent evolution of glass ionomers was the incorporation of ceramic fillers into glass ionomers. Amalgomer CR is a ceramicreinforced posterior glass ionomer containing $17 \%$ by weight 
zirconia fillers with an average particle size of $0.8 \mu \mathrm{m} .{ }^{9}$ The manufacturer claims that the material possesses compressive, tensile, and flexural strength close to that of amalgam. In addition, a sustained high level of fluoride release, modulus of elasticity close to that of dentin, superior esthetics, and superior radio-opacity have also been claimed. Even with the addition of ceramic fillers, it still retains the ability for chemical bonding to tooth structure and it has good working time. ${ }^{10,11}$

Accordingly, the objective of this study was to evaluate the effect of aging on some properties of ceramic-reinforced glass ionomers such as compressive strength, fluoride release, water sorption, and solubility and compare it to that of a resin-modified glass ionomer (Fuji VIII) and high-viscosity glass ionomer (Equia fill) restorative materials.

\section{Materials and Methods \\ Materials Used in the Study}

Materials used in the study, their composition, manufacturers, and lot number are listed in Table 1.

\section{Specimen Preparation and Material Testing Compressive Strength}

Specimens were prepared according to the ISO Guidelines No. 9917-1:2007(E). ${ }^{12}$ Materials were proportioned and mixed according to the manufacturers' instructions. The methods of specimen's preparation for each material are summarized in Table 2. After mixing, the material was packed in split Teflon mold with internal dimensions of $4 \mathrm{~mm}$ diameter and $6 \mathrm{~mm}$ thickness. The mold was placed on a glass slide, the material was then packed into the mold and covered with a celluloid strip and another glass on top. The mold and glass slides were clamped to apply equal pressure on the specimen using a screw clamp. The whole assembly was transferred to an incubator (Titanox, TITANOX art. A3-213-400I Co. Torrede Picenardi (CR), Italy) and kept at $37^{\circ} \mathrm{C}$ for 1 hour. The specimens were then removed from the mold, finished using wet silicon carbide paper, and the varnish was applied. Specimens were stored in deionized water at $37^{\circ} \mathrm{C}$ in the incubator according to the intended storage period: 24 hours or 6 months $(n=10)$. For compressive strength testing, the specimens were loaded under compression up to fracture using a universal testing machine (Instron ${ }^{\mathrm{TM}} 3365$ Massachusetts, UK) at a cross head speed of $1 \mathrm{~mm} / \mathrm{minute}$ till fracture. The compressive strength (CS) was calculated using Bluhill $3^{\circledR}$ software by applying the following equation: ${ }^{12}$

$$
\mathrm{CS}=4 P / \neq d^{2}
$$

where $P$ is the maximum applied load and $d$ is the diameter of the specimen.

\section{Fluoride Release}

Seven specimens ( $6 \mathrm{~mm}$ diameter and $3 \mathrm{~mm}$ thickness) for each group were prepared using split Teflon mold. ${ }^{13}$ Materials were proportioned and mixed according to the manufacturers' instructions as described in Table 2. After removal of the specimens from the mold, each specimen was immersed in $35 \mathrm{~mL}$ deionized water in plastic bottles and stored in the incubator at $37^{\circ} \mathrm{C}$ for 24 hours, 48 hours, 7 days, 1 month, 3 months, and after 6 months $(n=7)$. At the time of testing, each plastic bottle was shaken, then specimens were removed, washed with deionized water, dried, and then stored again in $35 \mathrm{~mL}$ of fresh deionized water and incubated. ${ }^{14}$ Total solubilized fluoride is determined using a fluoride ion-selective electrode (Orion EA 940, Thermo Electron Corporation, Houston, TX, USA). ${ }^{15}$

\section{Water Sorption and Solubility}

Specimens were prepared according to the ISO Guidelines No. 4049:2009(E). ${ }^{16}$ Five-disk specimens (15 mm diameter and $1 \mathrm{~mm}$ thickness) were prepared for each group using a split Teflon mold. The tested materials were proportioned and mixed according to the manufacturer's instructions (Table 2).

Specimens were removed from the mold and transferred to a desiccator containing silica gel and maintained at a temperature of $37^{\circ} \mathrm{C}$ for 22 hours. The desiccator was then maintained at a temperature of $23^{\circ} \mathrm{C}$ for 2 hours. The specimens were weighed three times using an analytical balance (Sartorius AZ 2014, Sartorius Mechatronics Corp, Bohemia, NY, USA) to an accuracy of $0.0001 \mathrm{~g}$, and the average of the three values was recorded. This cycle was repeated until a constant mass $m_{1}$ was reached.

Table 1: Materials used in the study, their composition, manufacturers, and lot numbers

\begin{tabular}{|c|c|c|c|}
\hline Material & Brand name and (manufacturer) & Composition & Lot number \\
\hline \multirow{3}{*}{$\begin{array}{l}\text { Ceramic-reinforced } \\
\text { glass ionomer }\end{array}$} & \multirow{3}{*}{$\begin{array}{l}\text { Amalgomer CR (Advanced } \\
\text { Healthcare Ltd, UK) }\end{array}$} & Powder/liquid & \multirow[t]{3}{*}{$111505-4$} \\
\hline & & $\begin{array}{l}\text { Powder: fluoroaluminosilicate glass, polyacrylic acid powder, } \\
\text { tartaric acid powder, and } 17 \% \text { by weight zirconia filler, } 0.8-\mu \mathrm{m} \\
\text { average particle size }\end{array}$ & \\
\hline & & Liquid: water & \\
\hline \multirow{3}{*}{$\begin{array}{l}\text { Resin-modified glass } \\
\text { ionomer }\end{array}$} & \multirow[t]{3}{*}{ Fuji VIII (GC America) } & Preweighted capsules & \multirow[t]{3}{*}{1707031} \\
\hline & & Powder: fluoroaluminosilicate glass, pigment & \\
\hline & & $\begin{array}{l}\text { Liquid: distilled water, polyacrylic acid, 2-HEMA, dimethacrylate, } \\
\text { and initiator }\end{array}$ & \\
\hline \multirow{3}{*}{$\begin{array}{l}\text { High-viscosity glass } \\
\text { ionomer }\end{array}$} & \multirow[t]{3}{*}{ Equia fill (GC America) } & Preweighted capsules & \multirow[t]{3}{*}{1605241} \\
\hline & & $\begin{array}{l}\text { Powder: } 95 \% \text { strontium fluoroaluminosilicate glass, } 5 \% \text { polyacrylic } \\
\text { acid }\end{array}$ & \\
\hline & & Liquid: $40 \%$ aqueous polyacrylic acid & \\
\hline $\begin{array}{l}\text { Low-viscosity nano-filled } \\
\text { surface coating resin }\end{array}$ & Equia coat (GC America) & (50\% methyl methacrylate and $0.09 \%$ camphor quinone) & 1604251 \\
\hline Glass ionomer varnish & Pyrax (Pyrax polymer) & Copal resin, acetone, and sodium fluoride & CV-001 \\
\hline
\end{tabular}

2-HEMA, 2-hydroxyethyl methacrylate 
Table 2: Methods of specimens' preparation for each material

\begin{tabular}{llll}
\hline Type of material & Method of specimens' preparation & Type of varnish & Method of varnish application \\
\hline $\begin{array}{l}\text { Ceramic-reinforced glass } \\
\text { ionomer (amalgomer CR) }\end{array}$ & $\begin{array}{l}\text { One scoop powder and one drop of liquid were } \\
\text { mixed }\end{array}$ & $\begin{array}{l}\text { Pyrax glass ionomer } \\
\text { varnish }\end{array}$ & $\begin{array}{l}\text { One layer of varnish was applied with } \\
\text { disposable brush on the surfaces of } \\
\text { the specimen and allowed to dry for } \\
40 \text { seconds }\end{array}$ \\
& $\begin{array}{l}\text { Half the powder was incorporated first into the } \\
\text { liquid as quickly as possible (5-10 seconds) and } \\
\text { then the remainder was added and spatulated to }\end{array}$ & $\begin{array}{l}\text { Another layer was applied and left to } \\
\text { dry }\end{array}$ &
\end{tabular}

then the remainder was added and spatulated to

a thick putty-like consistency

Total mixing time was 30 seconds

Resin-modified glass ionomer (Fuji VIII)

High-viscosity glass ionomer (Equia fill)
First, the plunger of the capsule was pressed, the capsule was inserted in the capsule applicator to activate it

The capsule was secured into the capsule holder of amalgamator (3M Capmix, 3M ESPE, Germany) to be mixed for 10 seconds

The capsule was inserted in the capsule applicator and squeezed into the mold

High-viscosity glass ionomer (Equia fill) specimens Equia coat were prepared following the same method described for Fuji VIII $\begin{array}{ll}\text { Pyrax glass ionomer } & \text { Pyrax glass ionomer varnish was } \\ \text { varnish } & \text { applied as previously mentioned }\end{array}$

\begin{tabular}{ll} 
described for Fuji VIII & $\begin{array}{l}\text { disposable brush, then each surface } \\
\text { was light cured for } 20 \text { seconds with } \\
\text { light cure (3M ESPE Elipar }{ }^{\mathrm{TM}} \text { ) }\end{array}$ \\
\hline
\end{tabular}

Two measurements of the diameter were taken, and the mean diameter was calculated using a digital caliper (Mitutoyo digimatic caliper, Mitutoyo Corp, Kawasaki, Japan) with a precision of $0.001 \mathrm{~mm}$. The thickness of the specimen was measured at the center of the specimen and at four equally spaced points on the circumference, and the mean thickness was calculated. The volume of the specimens in cubic millimeters was then calculated as follows: ${ }^{16}$

$$
V=\pi r^{2} h
$$

where $\pi=3.14, r=$ radius of the specimen (diameter/2), and $h=$ thickness of the specimen. After the constant mass $m_{1}$ was reached and the volume of the specimens was calculated, each specimen was stored in $10 \mathrm{~mL}$ of deionized water at a temperature of $37^{\circ} \mathrm{C}$ until time of testing. Specimens of each material were divided into four groups according to storage time. The water sorption and solubility were tested after 7 days, 1 month, 3 months, and 6 months from storage in water $(n=5)$.

\section{Scanning Electron Microscopic Evaluation}

Representative samples of the different tested glass ionomers after 7 days and 6 months water storage (water sorption and solubility specimens) were evaluated by an environmental scanning electron microscope (SEM; Quanta 250 FEG Field Emission Gun, The Netherlands), with an accelerating voltage of $30 \mathrm{kV}$. The surfaces to be evaluated were mounted on metallic stubs and evaluated by SEM at 2,000× magnification.

\section{Statistical Analysis}

Statistical analysis was performed with IBM ${ }^{\circledR}$ SPSS $^{\oplus}$ (SPSS Inc., IBM Corporation, NY, USA) Statistics Version 25 for Windows. Data were tested for normality and presented as mean and standard deviation (SD) values. For compressive strength results, two-way analysis of variance (ANOVA) followed by one-way ANOVA and Bonferroni correction for pairwise comparisons were used to compare different glass ionomer materials at each time interval. Independent $t$ test was carried out to compare between different time intervals for each material.

For fluoride release results, one-way ANOVA followed by pairwise comparisons with Bonferroni correction was used to compare different glass ionomer materials at each time interval, and repeated-measures ANOVA was used to compare between different time intervals of each material.

For water sorption and solubility results, two-way ANOVA followed by one-way ANOVA and Bonferroni correction for pairwise comparisons was used to compare between different materials and time intervals.

\section{Results}

\section{Compressive Strength Results}

For 24-hour groups, amalgomer CR and Fuji VIII showed the highest compressive strength with no significant difference between them. For 6-month groups, the compressive strength of amalgomer CR was significantly decreased. Mean and SD values for compressive strength $(\mathrm{MPa})$ of the different tested materials with time are presented in Table 3.

\section{Fluoride Release Results}

Amalgomer CR was found to have the highest fluoride-releasing capacity after 24 hours of storage in deionized water followed by Fuji VIII and Equia fill. The patterns of fluoride release at different time intervals of the three tested materials are presented in Figure 1.

\section{Water Sorption and Solubility Results}

For 7-day groups, Equia fill showed the least amount of sorption and solubility followed by amalgomer CR and Fuji VIII. The pattern of water sorption and solubility for all tested materials revealed an increase with aging in water. Mean and SD values for water sorption of the different tested materials are presented in Table 4. 
The pattern of solubility with time of the different tested materials is presented in Table 5 .

Pearson product-moment correlation coefficient was used and revealed a significant $(p<0.01)$ and positive correlation between the water sorption and solubility as shown in Figure 2.

\section{SEM Evaluation Results}

Scanning electron microscopic (SEM) images $(2,000 \times)$ of the tested materials after 7 days and 6 months water storage are

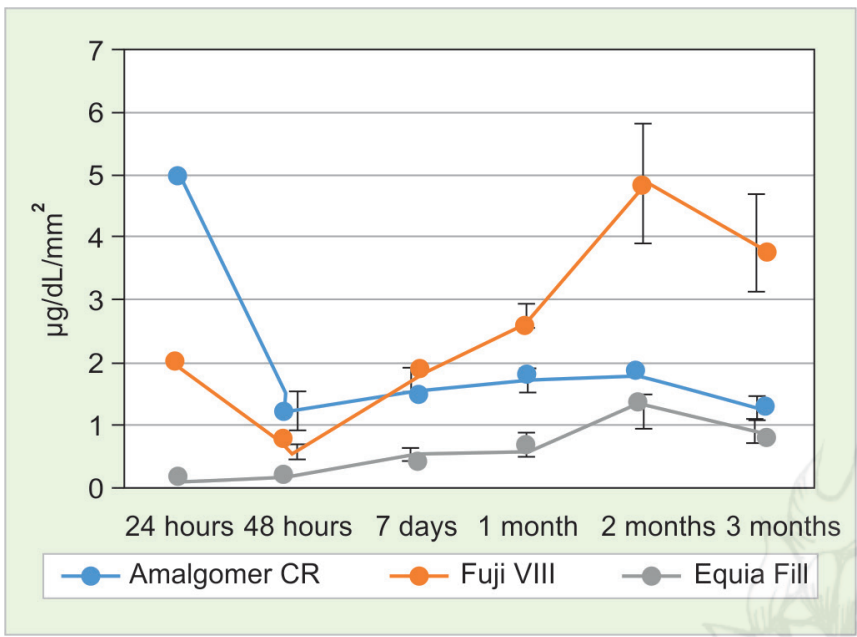

Fig. 1: Line chart showing the mean fluoride release and standard deviation (error bars) for different tested materials with time shown in Figures 3 to 5 . Figure 3 shows the SEM photomicrograph of amalgomer $\mathrm{CR}$ revealing the matrix of the material with glass and zirconia fillers (Fig. 3A). After 6 months of water aging, the surface showed zirconia fillers not bonded to the matrix, surface irregularities, and microporosities (Fig. 3B).

Figure 4 shows the microstructure of Fuji VIII revealing the glass fillers within the matrix, porosities, and filler dislodgment (Fig. 4A). After 6 months of aging, surface microcracks and concavities were observed (Fig. 4B).



Fig. 2: Scatter plot for the water sorption and solubility for different materials

Table 3: Mean and standard deviation (SD) values for compressive strength (MPa) of the different tested materials

\begin{tabular}{|c|c|c|c|c|c|c|}
\hline & & \multicolumn{4}{|c|}{ Time } & \multirow[b]{3}{*}{$p$ value } \\
\hline & & \multicolumn{2}{|c|}{24 hours } & \multicolumn{2}{|c|}{6 months } & \\
\hline & & Mean & $S D$ & Mean & $S D$ & \\
\hline \multirow{3}{*}{$\begin{array}{l}\text { Compressive } \\
\text { strength ( } \mathrm{MPa})\end{array}$} & Amalgomer CR & $152.75^{\mathrm{aA}}$ & 23.82 & $111.81^{\mathrm{aB}}$ & 24.50 & $\leq 0.001^{*}$ \\
\hline & Fuji VIII & $159.97^{\mathrm{aA}}$ & 15.72 & $151.47^{\mathrm{bA}}$ & 20.15 & $0.336 \mathrm{NS}$ \\
\hline & Equia fill & $105.95^{\mathrm{bB}}$ & 13.29 & $97.77^{\mathrm{aB}}$ & 8.54 & 0.355 NS \\
\hline$p$ value & & $\leq 0.001^{*}$ & & $\leq 0.001^{*}$ & & \\
\hline
\end{tabular}

Different lower-case letters within each column and upper-case letters within each row indicate significant difference; ${ }^{*}$ significant; NS, nonsignificant
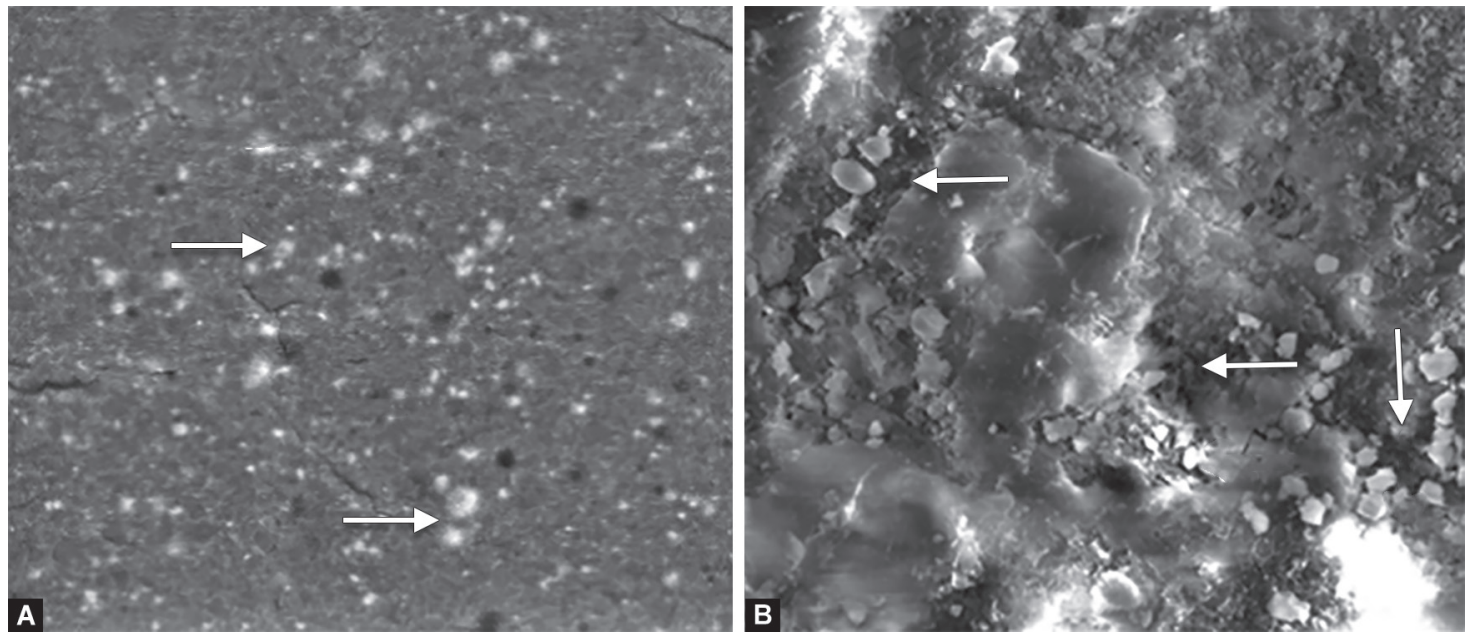

Figs $3 A$ and B: Scanning electron microscope photomicrograph (2,000x) of Amalgomer CR: (A) After 7 days of water storage; (B) After 6 months aging in water 
Table 4: Means and standard deviations (SD) for water sorption $\left(\mu \mathrm{g} / \mathrm{mm}^{3}\right)$ of the different tested materials

\begin{tabular}{|c|c|c|c|c|c|c|c|c|c|c|}
\hline & & \multicolumn{8}{|c|}{ Time } & \multirow[b]{3}{*}{$p$ value } \\
\hline & & \multicolumn{2}{|c|}{7 days } & \multicolumn{2}{|c|}{1 month } & \multicolumn{2}{|c|}{3 months } & \multicolumn{2}{|c|}{6 months } & \\
\hline & & Mean & $S D$ & Mean & $S D$ & Mean & $S D$ & Mean & $S D$ & \\
\hline \multirow{3}{*}{$\begin{array}{l}\text { Water sorption } \\
\left(\mu \mathrm{g} / \mathrm{mm}^{3}\right)\end{array}$} & Amalgomer CR & $144.92^{\mathrm{dB}}$ & 3.64 & $173.02^{\mathrm{CA}}$ & 7.76 & $184.94^{\mathrm{Ba}}$ & 3.67 & $238.11^{\mathrm{aA}}$ & 14.6 & $\leq 0.001$ \\
\hline & Fuji VIII & $170.10^{\mathrm{bA}}$ & 6.51 & $162.03^{\mathrm{bB}}$ & 3.92 & $164.85^{\mathrm{bB}}$ & 3.91 & $215.81^{\mathrm{aB}}$ & 5.91 & $\leq 0.001$ \\
\hline & Equia fill & $134.71^{\mathrm{bC}}$ & 2.17 & $137.64^{b c}$ & 6.01 & $151.55^{\mathrm{aC}}$ & 4.13 & $165.79^{\mathrm{aC}}$ & 9.14 & $\leq 0.001$ \\
\hline$p$ value & & $<0.001$ & & $<0.001$ & & $<0.001$ & & $<0.001$ & & \\
\hline
\end{tabular}

Different lower-case letters within each column and upper-case letters within each row indicate significant difference

Table 5: Mean and standard deviation (SD) values for solubility $\left(\mu \mathrm{g} / \mathrm{mm}^{3}\right)$ of the different tested materials

\begin{tabular}{|c|c|c|c|c|c|c|c|c|c|c|}
\hline & & \multicolumn{8}{|c|}{ Time } & \multirow[b]{3}{*}{$p$ value } \\
\hline & & \multicolumn{2}{|c|}{7 days } & \multicolumn{2}{|c|}{1 month } & \multicolumn{2}{|c|}{3 months } & \multicolumn{2}{|c|}{6 months } & \\
\hline & & Mean & $S D$ & Mean & $S D$ & Mean & $S D$ & Mean & $S D$ & \\
\hline \multirow{3}{*}{$\begin{array}{l}\text { Solubility } \\
\left(\mu \mathrm{g} / \mathrm{mm}^{3}\right)\end{array}$} & Amalgomer CR & $1.25^{\mathrm{bD}}$ & 0.22 & $39.06^{\mathrm{aC}}$ & 4.29 & $45.09^{\mathrm{aB}}$ & 1.47 & $50.28^{\mathrm{aA}}$ & 4.12 & $\leq 0.001$ \\
\hline & Fuji VIII & $8.03^{\mathrm{aC}}$ & 1.13 & $23.57^{\mathrm{bB}}$ & 2.11 & $23.74^{\mathrm{bB}}$ & 2.14 & $37.27^{\mathrm{bA}}$ & 3.49 & $\leq 0.001$ \\
\hline & Equia fill & $-1.935^{\mathrm{cC}}$ & 2.85 & $9.67^{\mathrm{CB}}$ & 1.16 & $11.54^{\mathrm{CB}}$ & 1.57 & $28.92^{\mathrm{CA}}$ & 3.36 & $\leq 0.001$ \\
\hline$p$ value & & $\leq 0.001$ & & $\leq 0.001$ & & $\leq 0.001$ & & $\leq 0.001$ & & \\
\hline
\end{tabular}

Different lower-case letters within each column and upper-case letters within each row indicate significant difference
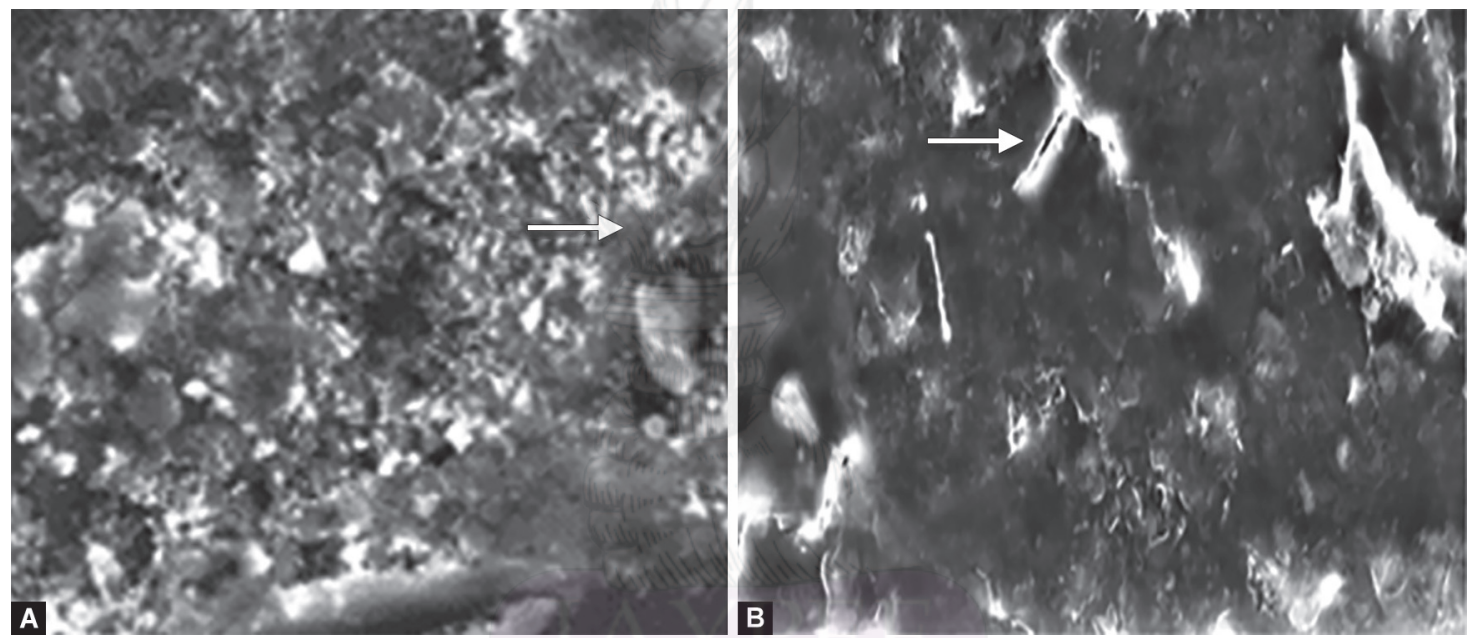

Figs 4A and B: Scanning electron microscope photomicrographs $(2,000 \times)$ of Fuji VIII: (A) After 7 days of water storage; (B) After 6 months aging in water
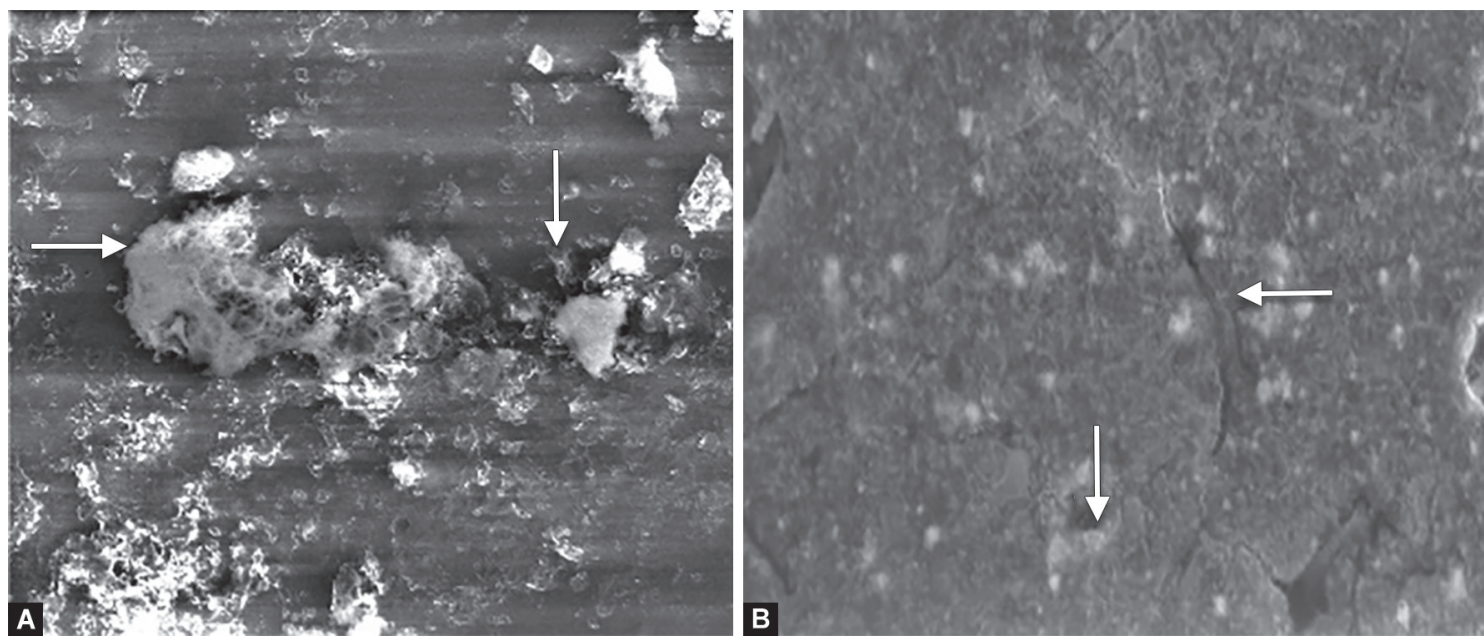

Figs 5A and B: Scanning electron microscope photomicrograph $(2,000 \times)$ of Equia fill: (A) After 7 days of water storage; (B) After 6 months aging in water 
Figure 5 reveals SEM photomicrograph of Equia fill showing Equia fill covered by Equia coat, which obliterates the surface details and causes closure of pores (Fig. 5A). 6 months of water aging showed dissolution of the coat with surface microporosities and microcracks (Fig. 5B).

\section{Discussion}

Compressive strength could be considered a critical indicator of success because materials with high compressive strength can withstand masticatory and parafunctional forces. Amalgomer CR and Fuji VIII showed the highest compressive strength after 24 hours of water storage followed by Equia fill. The early strength of glass ionomers is principally affected by the chemical composition, the microstructure of the glass, the nature of polyacrylic acid, and the powder to liquid ratio. These factors may also be responsible for the variations observed with time. ${ }^{17}$

For amalgomer $\mathrm{CR}$, the high compressive strength could be attributed to their zirconia filler content $(17 \%$ by weight particulate zirconia fillers, $0.8 \mu \mathrm{m}$ average particle size), which was found to be effective in strengthening of glass ionomers. ${ }^{18,19}$ The high compressive strength of Fuji VIII might be related to their structure after chemical setting. It was found that when the acid-base reaction is supplemented by a polymerization process, the resulting structure is an interpenetrating network of poly-HEMA and polyacid salts that strengthen the matrix formed. ${ }^{20}$

The compressive strength of amalgomer CR showed a significant decrease after 6 months of aging in deionized water, whereas the Fuji VIII and Equia fill maintained their compressive strength. Although there was a decrease in the compressive strength of amalgomer CR throughout the 6 months, it still fulfills the ISO guidelines no. 9917-1:2007(E) for water-based cements, which indicated that the minimum compressive strength required for glass ionomer as a restorative material is $100 \mathrm{MPa}^{12}$ The addition of zirconia fillers to amalgomer CR increased its compressive strength after 24 hours, but probably the lack of bonding between these fillers and the glass matrix might lead to an increase in the microporosities, making the material more prone to water sorption, deterioration, and loss of strength by aging in water. ${ }^{17}$ This was further justified by water sorption results, which showed a significant increase in water sorption by time and SEM photomicrographs, which showed surface irregularities, microporosities, and poor bonding between zirconia fillers and the matrix (Fig. 3B).

This was in agreement with the study by Wang and Darvell ${ }^{17}$ in which they concluded that the wet storage has a detrimental effect on ceramic-reinforced glass ionomers, which may indicate long-term deterioration in service.

In this study, the deionized water was used as a specimen storage solution for fluoride release measurement, as it provides the baseline of fluoride release under unstimulated conditions. ${ }^{21}$ All glass ionomers evaluated in this study released measurable amounts of fluoride, which was highest on the first day and then sharply decreased on the second day until reaching a low long-term release. This is a normal feature of glass ionomers and is called the Burst Effect. The burst effect is probably associated with the release of fluoride, which is loosely bound in the glass ionomer and originates from the initial acid-base reaction between the glass and acid. ${ }^{22}$ The later gradual release is accompanied by the second bulk diffusion process by which small amounts of fluoride continue to be released through the material matrix pores. ${ }^{2,22}$
Amalgomer CR revealed the highest fluoride releasing capacity, on the first day of storage in deionized water, when compared with other materials within this study. This may be related to the type of fillers. A study conducted by Thanjal et al. ${ }^{23}$ compared the fluoride release of a glass ionomer containing zirconia as a reinforcing filler (amalgomer CR) with a zirconia-free glass ionomer and showed that the presence of inert zirconia secondary filler enhances fluoride release. Also, the bonding between the fillers and the matrix could be a factor. It was revealed that the lack of bonding between the ceramic zirconia particles and the matrix of amalgomer CR may have led to an increase in the microporosities, which in turn can facilitate fluoride release. ${ }^{24}$

In the present study, resin-modified glass ionomer (Fuji VIII) showed less fluoride release initially compared to ceramicreinforced glass ionomers. This could be attributed to its setting reaction, in which both polymerization and acid-base reaction takes place, and the polymerization reaction precedes the acidbase reaction. ${ }^{14,25}$ The delayed acid-base reaction may result in releasing less fluoride initially at the first day.

The pattern of fluoride release of Equia fill was different from other experimental materials. The burst initial release on the first day was low, which contradicts with what usually happens, and then began to slightly increase after a week. This might be explained by the resin surface coating of the Equia coat that was applied according to the manufacturer's instructions. This coat is a nanofilled resin with low viscosity, which can penetrate and close surface porosities.

One of the main factors that determine the durability of a material used in the oral environment is its stability in aqueous environment. Saliva in the oral environment is a diluted fluid comprising more than $99 \%$ water in addition to dissolved inorganic and organic solids. So, water was used to evaluate the weight gain of restorative materials. For 7-day groups, Equia fill showed the least amount of water sorption followed by amalgomer CR, whereas Fuji VIII showed the highest value. The pattern of water sorption for all tested materials revealed an increase with aging in deionized water up to 6 months' time period, where Equia fill still showed the least amount of water sorption, whereas amalgomer CR and Fuji VIII showed higher values.

During water storage, two different mechanisms occur; the first is the uptake of water producing an increased weight, and the second is the dissolution of materials (fillers or monomers) in water, leading to a weight reduction of the final conditioned samples. The amount of water absorbed inside the material can be related to the amount of microporosities inside the structure and presence of hydrophilic groups in the material. Equia fill showed the least amount of water sorption, which could be attributed to their high viscosity that leads to less microporosities in the structure, making them less prone to absorb water. In addition, the low-viscosity nanofilled resin surface coating of Equia fill that was applied according to the manufacturer's instructions may contribute to the low amount of water sorption through penetration and closure of surface porosities. This was further justified by SEM photomicrographs (Fig. 5A), which showed layer of coat obliterating the surface of Equia fill specimen.

On the contrary, in amalgomer $\mathrm{CR}$, the coarse ceramic particles with the poor bonding to the matrix could increase the microporosities that made the material more prone to water sorption. The high amount of water sorption for Fuji VIII may be explained by the presence of hydrophilic resin components in its composition. Beriat and Nalbant ${ }^{26}$ proposed that hydrophilic 
constituents such as HEMA clearly increased the water sorption values of resin-modified glass ionomer. This was in agreement with the study by Bamise et al., ${ }^{7}$ who evaluated water sorption of amalgomer CR and Fuji IX (highly viscous glass ionomer) after 120 hours and revealed that amalgomer CR showed the highest weight gain in the water, Coke, and Fanta.

The solubility of dental restorative materials influences both their rate of degradation and their biological compatibility. For 7-day groups, Equia fill showed the least amount of solubility followed by amalgomer CR and Fuji VIII. The pattern of solubility increased with time.

Equia fill showed the least amount of solubility among all tested groups. This may be explained by the faster maturation of the highviscosity glass ionomers owing to their chemically modified powder during manufacturing where the calcium content was decreased and replaced by strontium that limits the production of calcium polyalkenoate chains that are highly water soluble. ${ }^{7}$ The higher initial solubility of Fuji VIII compared to other groups could be represented by the amount of residual monomers leached out from the cements. ${ }^{27}$ Pearson correlation coefficient revealed statistical significance $(p<0.01)$ and positive correlation between the water sorption and solubility, indicating that more water sorption resulted in more amount of solubility of the material.

Based on the results obtained in the current study, it could be concluded that the addition of zirconia fillers to glass ionomers (amalgomer CR) improved the tested physical and mechanical properties; however, this improvement was reduced by aging in water.

\section{References}

1. Cury JA, de Oliveira BH, dos Santos AP, et al. Are fluoride releasing dental materials clinically effective on caries control? Dent Mater 2016;32(3):323-333. DOI: 10.1016/j.dental.2015.12.002.

2. Bansal R, Bansal T. A Comparative evaluation of the amount of fluoride release and re-release after recharging from aesthetic restorative materials: an in vitro study. J Clin Diagn Res 2015;9(8):Zc11-Zc14. DOI: 10.7860/JCDR/2015/11926.6278.

3. Wilson AD. Resin-modified glass-ionomer cements. Int J Prosthodont 1990;3(5):425-429.

4. Sidhu SK. Glass-ionomer cement restorative materials: a sticky subject? Aust Dent J 2011;56(Suppl 1):23-30. DOI: 10.1111/j.18347819.2010.01293.x.

5. Smithson J. Technique tips--the modified super-closed sandwich technique. Dent Update 2013;40(2):155-156.

6. Mickenautsch S. High-viscosity glass-ionomer cements for direct posterior tooth restorations in permanent teeth: the evidence in brief. J Dent 2016;55:121-123. DOI: 10.1016/j.jdent.2016.10.007.

7. Bamise C, Mejabi M, Esan T. Short term sorption effect on three esthetic dental filling materials in various media. Adv Res 2015;5(6): 1-9. DOI: 10.9734/AIR/2015/20183.

8. Gurgan S, Kutuk ZB, Ergin E, et al. Clinical performance of a glass ionomer restorative system: a 6-year evaluation. Clin Oral Investig 2017;21(7):2335-2343. DOI: 10.1007/s00784-016-2028-4.
9. Cugati N, Bhat SS, Hegde SK. Comparison of anticariogenic effect of Amalgomer CR, Fuji VII and Heliomolar Refill in the cavosurface margin-An in-vitro study. J Contemp Dent Pract 2011;2(3).

10. Billington R. Glass ionomer come of age. Dentist 2004; 2-3.

11. Bariker RH, Mandroli PS. An in-vitro evaluation of antibacterial effect of Amalgomer CR and Fuji VII against bacteria causing severe early childhood caries. J Indian Soc Pedod Prev Dent 2016;34(1):23. DOI: 10.4103/0970-4388.175506.

12. Dentistry-water-based cements Part, I., Powder/liquid acid-base cements. ISO: 9917-1.

13. Rao BS, Moosani GK, Shanmugaraj M, et al. Fluoride release and uptake of five dental restoratives from mouthwashes and dentifrices. $J$ Int Oral Health 2015;7(1):1-5.

14. Patil S, Goud K, Sajjan G. Fluoride release from various restorative materials over a 3 month period-an in vitro study. J Pierre Fauchard Acad 2012;26(1):30-34. DOI: 10.1016/S0970-2199(12)61006-6.

15. Mousavinasab SM, Meyers I. Fluoride release and uptake by glass ionomer cements, compomers and Giomers. Res J Biol Sci 2009;4(5):609-616.

16. ISO. Dentistry-polymer-based restorative materials. Geneva, Switzerland: International Organization for Standardization; 2009.

17. Wang Y, Darvell B. Hertzian load-bearing capacity of a ceramicreinforced glass ionomer cement stored wet and dry. Dent Mater 2009;25(8):952-955. DOI: 10.1016/j.dental.2009.02.006.

18. Gu Y, Yap AUJ, Cheang P, et al. Zirconia-glass ionomer cement-a potential substitute for Miracle Mix. Scrip Mater 2005;52(2):113-116. DOI: 10.1016/j.scriptamat.2004.09.019.

19. Abdulsamee N, Elkhadem AH. Zirconomer and zirconomer improved (White Amalgams): restorative materials for the future. Review. EC Dent Sci 2017;15:134-150.

20. Mitra SB, Kedrowski BL. Long-term mechanical properties of glass ionomers. Dent Mater 1994;10(2):78-82. DOI: 10.1016/01095641(94)90044-2.

21. Nigam AG, Jaiswal J, Murthy R, et al. Estimation of fluoride release from various dental materials in different media - an in vitro study. Int J Clin Pediatr Dent 2009;2(1):1. DOI: 10.5005/jp-journals-10005-1033.

22. Upadhyay S, Rao A, Shenoy R. Comparison of the amount of fluoride release from nanofilled resin modified glass ionomer, conventional and resin modified glass ionomer cements. J Dent 2013;10(2):134-140.

23. Thanjal N, Billington RW, Shahid S, et al. Kinetics of fluoride ion release from dental restorative glass ionomer cements: the influence of ultrasound, radiant heat and glass composition. J Mater Sci Mater Med 2010;21(2):589-595.

24. Bahadure R, Pandey RK, Kumar R, et al. An estimation of fluoride release from various dental restorative materials at different $\mathrm{pH}$ : in vitro study. J Indian Soc Pedod Prev Dent 2012;30(2):122. DOI: 10.4103/0970-4388.99983.

25. Kim YK, Kim K-H, Kwon T-Y. Setting reaction of dental resinmodified glass ionomer restoratives as a function of curing depth and postirradiation time. J Spectrosc 2015; 462687. DOI: 10.1155/2015/462687.

26. Beriat NC, Nalbant D. Water absorption and HEMA release of resinmodified glass-ionomers. Eur J Dent 2009;3(4):267. DOI: 10.1055/s0039-1697443.

27. Kanchanavasita W, Anstice H, Pearson GJ. Water sorption characteristics of resin-modified glass-ionomer cements. Biomaterials 1997;18(4):343-349. DOI: 10.1016/S0142-9612(96)00124-X. 